\title{
Does psychotherapy improve alexithymia? A comparison study among patients with mild or moderate depression
}

\author{
ONUR YILMAZ1 \\ https://orcid.org/0000-0002-8270-7354 \\ Ali Barlas MirçIK ${ }^{1}$ \\ https://orcid.org/0000-0001-8192-9249 \\ Merve KunduZ ${ }^{1}$ \\ https://orcid.org/0000-0003-4161-4773 \\ MÜGe Combaş 1 \\ https://orcid.org/0000-0003-1536-0458 \\ AHMET ÖZTÜRK ${ }^{1}$ \\ https://orcid.org/0000-0002-9854-7586 \\ ERdem DeVeci ${ }^{1}$ \\ https://orcid.org/0000-0002-9661-8344 \\ ISMET KIRPINAR ${ }^{1}$ \\ https://orcid.org/0000-0001-9816-3438 \\ 1 Bezmialem Foundation University Medical Faculty, Department of Psychiatry, Istanbul, Turkey. \\ Institution where the study was conducted: Bezmialem Foundation University Medical Faculty, Department of Psychiatry, Istanbul, Turkey.
}

Received: 02/10/2019 - Accepted: 09/04/2019

DOl: 10.1590/0101-60830000000217

\begin{abstract}
Background: Alexithymia is reported to be a risk factor for depression. Psychotherapy is efficient for treatment of depression. Yet, the effect of psychotherapies on alexithymia is poorly understood. Objectives: We aimed to compare Cognitive Behavioral Therapy (CBT), Existential Psychotherapy (ExP) and Supportive Counseling (SUP) for therapeutic efficacy and effect on alexithymia in depression. Methods: There were 22 patients for each patient group. Sessions were performed as eight consecutive weekly and following two monthly boosters. Sixty six healthy controls were added. Prior to the sessions, patients received Sociodemographic Data Form, the Structured Clinical Interview for DSM-IV Axis I Disorders (SCID-1), Hamilton Depression Rating Scale (HDRS) and 20 -item Toronto Alexithymia Scale (TAS-20). The control group received Sociodemographic Data Form, SCID-1 and TAS-20. Patients additionally received HDRS and TAS-20 after their weekly and booster sessions. Results: Patients' mean TAS-20 score was greater than of controls, however, it did not have a significant change throughout the study. Mean HDRS scores of ExP and CBT groups were lower than SUP group at the end. Discussion: Alexithymia did not improve with psychotherapy. The exception was effect of ExP on externally oriented thinking. Psychotherapies all improved depression. CBT and ExP were more helpful than SUP.
\end{abstract}

Yilmaz O et al. / Arch Clin Psychiatry. 2019;46(6):156-64

Keywords: Alexithymia, cognitive behavioral therapy, depression, existential psychotherapy, supportive counselling.

\section{Introduction}

The word alexithymia was suggested by Sifneos, from the Greek $(\mathrm{a}=\text { lack, lexis }=\text { work, thymos }=\text { mood or emotion })^{1}$. Alexithymic individuals have difficulty in recognizing their emotions, expressing them and manifesting them by linking emotions and thoughts. People with alexithymia were reported to prominently be unable to benefit from social support because of their cognitive deficits of emotion ${ }^{2}$. In furtherance, alexithymia was reported to be connected to $\mathrm{MDD}^{3}$. Alexithymia is not only seen in MDD or other psychiatric disorders, but also in psychosomatic disorders ${ }^{4}$ and systemic disorders like hypertension ${ }^{5}$. It should be noticed that, alexithymic signs are not absolutely pathological. They may also be seen in general population to some extent ${ }^{6,7}$. Various research reported the prevalence of alexithymia (TAS-20 total score $\geq 61$ ) to be between 12 and $18 \%$, besides, results about gender differences were contradictory ${ }^{8,9}$.

Depression is the most frequent type of mood disorders. It may cause significant burden of life and mortality ${ }^{10}$. Major depressive disorder (MDD) is estimated to reach the second rank among causes of disability by the year $2020^{11}$.

Cognitive behavioral therapy (CBT) is one of the widely and successfully used psychotherapy models for MDD. CBT is developed and put into practice firstly by Beck et al. ${ }^{12}$. As time goes by, retrospective studies and reviews about CBT for depression have been added to literature ${ }^{13,14}$. Several trials reported enduring effects of CBT delivered during acute phase of MDD, which was unlikely with antidepressants $(\mathrm{AD})^{15}$. While traditional CBT is not beneficial enough in some cases, relatively new approaches on the field, called third wave CBT, have come to the scene. Several third wave CBT methods have been declared and empirically supported to be helpful for particular forms of depression ${ }^{16}$. The terms acceptance and mindfulness, which are closely related to existential phylosophy, are widely used among third wave CBT literature and practice ${ }^{17,18}$.

Existential philosopy focuses mainly on meaning of life, freedom, authenticity and responsibility ${ }^{19-22}$. Existential Psychotherapy $(\mathrm{ExP})^{\star}$ is based on existential philosophy. That is to say, a psychotherapy model is called existential therapy only if it is based on phylosophy, rather than psychologic theories. The interview between the therapist and the patient in an existential psychotherapy session is based on

* There are no declared generic names or abbreviations for existential psychotherapies as a whole. Therefore, we named an abbreviation on our own behalf. 
the method called phenomenology ${ }^{23}$. Phenomenologic dialogue is a kind of invitation to the individual to let happenings and things to demonstrate themselves just like what actually they are ${ }^{24}$. Existential philosophy has an ancient course. Australian psychiatrist and psychotherapist Viktor Emile Frankl is generally accepted to be the first therapist who performed his work on the basis of existential philosophy. While it is roughly accepted that each existential therapist has his/her own way of performing ExP, Frankl's approach on existential psychotherapy has a particular name, logotherapy $(\mathrm{LT})^{25}$. LT is generally understood as "meaning therapy" and has been practiced by a large number of psychotherapists. There are also many other schools of existential psychotherapy, some of which are entitled as Dasein Analysis ${ }^{26}$, Existential Group Therapy ${ }^{27}$ and Existential Couple Therapy ${ }^{28}$. However, LT or other ExP echoles did not take part in guidelines for depression treatment yet.

A group of researchers performed unstructured forms of psychotherapy which does not help through specific psychological techniques. These nondirective therapies are commonly described in the literature as either counselling or supportive therapy. Though less effective than other therapies, nondirective supportive therapies were reported to be helpful for depressed patients29,30.

Given alexithymia is a potent risk factor for MDD and various psychotherapy echoles are proven to improve MDD significantly, we investigated effects of psychotherapies on alexithymia among MDD patients. We also compared the therapeutic effects of CBT, ExP and SUP against MDD. To the best of our knowledge, no previous study comparing CBT and ExP for treatment of MDD was performed.

\section{Methods}

Our study was performed at Bezmialem Foundation University Psychiatry Clinics. The study protocol was approved by Bezmialem Foundation University Ethics Committee for Interventional Studies (approval date: 07.02.2017; approval number: 3/21).

\section{Subjects}

One hundred two patients in total, who were diagnosed with mild or moderate MDD were selected throughout the study. Sixty-six patients $(64,7 \%)$ completed the whole protocol. The control group consisted of 66 healthy volunteers, matched with the patient group for age, education and gender. All subjects were selected from individuals aged between 18 and 65 years. Patients who had comorbid psychiatric disorders such as obsessive compulsive disorder (OCD), severe personality disorders, post traumatic stress disorder (PTSD), substance-related and addictive disorders; patients who have bipolar affective disorder (BPD) and patients who had been on psychiatric medication from two months before the evaluation date for the study were not included. Individuals hard to communicate, such as patients with dementia, blindness and deafness were not included either.

Seventy-three individuals were selected for healthy control group throughout the process. Seven out of them were excluded, due to axis-1 psychiatric disorders, identified by performing The Structured Clinical Interwiev for DSM-IV TR Axis-1 Disorders (SCID-I) and psychiatric examination. Employees working at Bezmialem Foundation University Hospital were not included, for avoiding an unfavorable situation concerning ethics. After making necessary explanations about the study, subjects who agreed to participate, have signed voluntary informed consent forms.

Among 66 patients who completed the whole study protocol, 22 $(33,3 \%)$ got CBT, $22(33,3 \%)$ got ExP and the rest $22(33,3 \%)$ got SUP for eight consecutive weekly sessions and the following two monthly booster sessions. Selection of patients and therapy models were made by two separate psychiatrists who were not on the therapist list. The selection model was randomisation, in which the subjects were directed to groups one by one, in order of CBT, ExP and SUP, till the number of subjects completed the study reached to the amount targetted. When necessary number was fulfilled, psychiatrists who select cases were informed by the therapists, in order not to direct any more patients.
Duration of sessions were 45 to 50 minutes. Ten patients selected for CBT $(31,2 \%), 12$ selected for $\operatorname{ExP}(35,3 \%)$ and 14 selected for SUP $(38,9 \%)$ did not complete the whole study. Three patients selected for CBT, four for ExP and five for SUP did not start sessions. Thus, 66 out of 90 starters $(73,3 \%)$ finished the trial. Two patients in CBT group, three in ExP group and two in SUP group did not continue after their first sessions. Throughout weekly sessions, one patient in CBT group, two in ExP group and one in SUP group were excluded from the study and directed to psychiatry clinics back, because of worsening of the symptoms to the extent that the diagnosis differed to severe MDD and they were supposed to be on psychiatric medication. Two patients in CBT group, two in ExP group and four in SUP group left the study from second to seventh of weekly sessions. Two patients in CBT group, one in ExP group and two in SUP group completed the weekly sessions, however, did not come for booster sessions.

Prior to the therapy sessions, patients received Sociodemographic Data Form prepared for the study, SCID-I, 20 item Toronto Alexithymia Scale (TAS-20) and Hamilton Depression Rating Scale (HDRS). The control group received Sociodemographic Data Form, SCID-I and TAS-20. Each patient received TAS-20 and HDRS twice more, former after weekly sessions and the latter after booster sessions.

The Structured Clinical Interview for DSM-IV Axis 1 Disorders (SCID-I): It is a form for psychiatric interview for axis-1 disorders identified in DSM-IV, structured by First et al. ${ }^{31}$. Adaptation to Turkish and reliability analysis of Turkish form were performed by Özkürkçügil et al. ${ }^{32}$.

Hamilton Depression Rating Scale (HDRS): Developed originally by Hamilton for measurement of severity of depressive symptoms ${ }^{33}$, the structured form was developed by Williams ${ }^{34}$. The validity and reliability study of Turkish form was performed by Akdemir et al. ${ }^{35}$.

20-Item Toronto Alexithymia Scale (TAS-20): It is a Likert type self report scale. Each item is scored between 1 and 5. Some items are scored in reverse order. There are three subscales as follows: Difficulty in Identifying Feelings (TAS-1), Difficulty in Describing Feelings (TAS-2) and Externally Oriented Thinking (TAS-3). It is considered that, as the scale total score gets higher, level of alexithymia gets higher. The scale was developed by Bagby et al. ${ }^{36}$. Turkish adaptation study was performed by Güleç et al. ${ }^{37}$. Scale total scores are categorized according to the cutoff points such that, a total score of $\geq 61$ points indicates alexithymia, and $\leq 51$ points indicates no alexithymia.

\section{Therapists and sessions}

Before study beginned, flowcharts for CBT and ExP were prepared (Figures 1 and 2). As it should be, there was no flowchart for SUP. First booster sessions were performed four weeks after weekly sessions have been completed. Second booster sessions were performed four weeks after the first booster.

Two therapists performed traditional CBT, two therapists performed ExP and one clinical psychologist, performed SUP. One of our CBT therapists, aged 63, was certified by Turkish Association for Cognitive and Behavioral Therapy (Istanbul, Turkey) and by Academy of Cognitive Therapy (Philadelphia, United States). Other CBT therapist, aged 25, was certified by Turkish Association of Psychiatry (Ankara, Turkey). ExP therapists, aged 40 and 31, were both certified by Existential Academy of Istanbul, which is affiliated to Viktor Franl Institute of Logotherapy (Dallas, Texas). Our SUP therapist, while SUP is not entirely considered to be a professional psychotherapeutic approach, was not specified on any psychotherapy echoles, however, she was a clinical psychologist. The durations of experience as psychotherapists and the number of patients with whom they performed and completed therapy sessions were as follows: 2 years (10 patients) and 6 years (12 patients) for CBT therapists, 2 years ( 9 patients) and 5 years (13 patients) for ExP therapists and 5 years (22 patients all) for SUP therapist. In this way, we intended to minimize the possible inequality regarding the therapy offered to patients and provide the utmost uniformity. 
Figure 1. Flowchart for CBT sessions

\begin{tabular}{|c|c|}
\hline $\begin{array}{l}\text { Session } \\
\text { number }\end{array}$ & Content of session in brief \\
\hline W1 & $\begin{array}{l}\text { Noting current complaints, } \\
\text { Getting brief knowledge about patient's history of disorder, } \\
\text { pharmacotherapy and psychotherapy (if any), } \\
\text { Showing some cognitive contradictions, } \\
\text { Setting appropriate and available targets, } \\
\text { Proposing treatment rationale for the agenda. }\end{array}$ \\
\hline W2 & $\begin{array}{l}\text { Discussing available cognitive contradictions and showing some } \\
\text { more, } \\
\text { Mentioning the term "automatic thoughts" and deriving them from } \\
\text { existing contradictions, } \\
\text { Demonstrating possible initiating, triggering and maintaininig factors, } \\
\text { Setting homework(s). }\end{array}$ \\
\hline W3 & $\begin{array}{l}\text { Evaluation of homework(s), } \\
\text { Exploring more automatic thoughts and evaluating alternative } \\
\text { thoughts against them, } \\
\text { Elaborating triggering and maintaining factors, } \\
\text { Setting new homework(s). }\end{array}$ \\
\hline W4 & $\begin{array}{l}\text { Evaluation of homework(s), } \\
\text { Testing certain automatic thoughts and elaborating more, } \\
\text { Evaluating alternative thoughts, } \\
\text { Retracing triggering and maintaining factors, } \\
\text { Setting new homework(s). }\end{array}$ \\
\hline W5 & $\begin{array}{l}\text { Evaluation of homework(s), } \\
\text { Testing and evaluating more (new, if explored any) automatic } \\
\text { thoughts, } \\
\text { Elaborating and retracing initiating factors, } \\
\text { Mentioning the term "intermediary beliefs" and deriving some of } \\
\text { them from outcomes until then, } \\
\text { Setting new homework(s). }\end{array}$ \\
\hline W6 & $\begin{array}{l}\text { Evaluation of homework(s), } \\
\text { Elaborating and testing intermediary beliefs, } \\
\text { Evaluating original and current targets, } \\
\text { Setting new homework(s). }\end{array}$ \\
\hline W7 & $\begin{array}{l}\text { Evaluation of homework(s), } \\
\text { Testing more (new, if explored any) intermediary beliefs, } \\
\text { Retracing initiating factors, } \\
\text { Setting new homework(s). }\end{array}$ \\
\hline W8 & $\begin{array}{l}\text { Evaluation of homework(s), } \\
\text { Overall assessment of alternative automatic thoughts and } \\
\text { intermediary beliefs, } \\
\text { Overall assessment of original and current targets, } \\
\text { Setting new (monthly) homework(s). }\end{array}$ \\
\hline B1 & $\begin{array}{l}\text { Evaluation of homework(s), } \\
\text { Overall assessment of alternative automatic thoughts and } \\
\text { intermediary beliefs, } \\
\text { "Mentioning the term "core beliefs" and deriving some from } \\
\text { intermediary beliefs (if needed), } \\
\text { Overall assessment of original and current targets, } \\
\text { Setting new (monthly) homework(s). }\end{array}$ \\
\hline B2 & $\begin{array}{l}\text { Overall assessment of alternative automatic thoughts and } \\
\text { intermediary beliefs (and core beliefs if needed), } \\
\text { Overall assessment of original and current targets, } \\
\text { Evaluating how to use new skills in case of relapse and } \\
\text { recurrence. }\end{array}$ \\
\hline
\end{tabular}

Notes: Despite following this flowchart, sessions were flexible to some extent, according to patients' needs and circumstances. Hamilton Depression Rating Scale and 20-item Toronto Alexithymia Scale were repeated after W8 and B2. ${ }^{*}$ Core beliefs are not usually needed to be explored for mild and moderate depression. Abbreviations: CBT: cognitive behavioral therapy; W: weekly session; B: booster session.
Figure 2. Flowchart for ExP sessions

\begin{tabular}{|c|c|}
\hline $\begin{array}{l}\text { Session } \\
\text { number }\end{array}$ & Content of session in brief \\
\hline W1 & $\begin{array}{l}\text { Noting current complaints, } \\
\text { Getting brief knowledge about patient's history of disorder, } \\
\text { pharmacotherapy and psychotherapy (if any), } \\
\text { Introducing basic route for ExP and assessing suitability of patient. }\end{array}$ \\
\hline W2 & $\begin{array}{l}\text { Letting the patient give more details of complaints, } \\
\text { Trying to cover how authentic is patient's life and which obstacles are } \\
\text { working against authenticity, } \\
\text { Trying to cover which aspects of patient's life are already close to } \\
\text { authenticity. }\end{array}$ \\
\hline W3 & $\begin{array}{l}\text { Structuring the therapeutic dialogue on phenomenologic basis, } \\
\text { Exploring intangible statements and directing the patient to embody } \\
\text { his/her speech, } \\
\text { Demonstrating how apart the patient is from or how close to } \\
\text { authenticity in certain fields. }\end{array}$ \\
\hline W4 & $\begin{array}{l}\text { Improving the phenomenologic dialogue, } \\
\text { Improving embodiment of patient's statements, } \\
\text { Assessment for patient's stance toward self-relatedness, } \\
\text { Directing the patient to express him/herself including physical, } \\
\text { relational and spiritual fields of living. }\end{array}$ \\
\hline W5 & $\begin{array}{l}\text { Improving the phenomenologic dialogue, } \\
\text { Exploring curbs resulting from avoiding embodiment, } \\
\text { Exploring the patient's stance toward responsibility and choices of life. }\end{array}$ \\
\hline W6 & $\begin{array}{l}\text { Improving the phenomenologic dialogue } \\
\text { Trying to receive feedbacks concerning patient's certain patterns } \\
\text { interfering with functionality, } \\
\text { Exploring curbs resulting from avoiding responsibility, } \\
\text { Directing the patient to negotiate about taking the responsibility of } \\
\text { his/her choices. }\end{array}$ \\
\hline W7 & $\begin{array}{l}\text { Improving the phenomenologic dialogue, } \\
\text { Inviting the patient to give feedbacks about his/her patterns } \\
\text { interfering with functionality, } \\
\text { Exploring curbs resulting from avoiding responsibility and freedom, } \\
\text { Directing the patient to negotiate about taking the responsibility of } \\
\text { predictible and unpredictible outcomes of his/her choices. }\end{array}$ \\
\hline W8 & $\begin{array}{l}\text { Improving the phenomenologic dialogue, } \\
\text { Inviting the patient to give feedbacks about his/her feelings about the } \\
\text { sessions and the therapist, } \\
\text { Exploring strengths of the patients that might have been gained } \\
\text { through enhanced sense of responsibility, } \\
\text { Inviting the patient to negotiate about his/her fears concerning freedom. }\end{array}$ \\
\hline B1 & $\begin{array}{l}\text { Evaluation of experiences until session date, } \\
\text { Overall assessment of the patient's stance toward responsibility, } \\
\text { authenticity and freedom, } \\
\text { Overall assessment of patient's stance toward desirable and } \\
\text { undesirable experiences, } \\
\text { Directing the patient to talk about his/her experiences with minimized } \\
\text { labels and habitual attitudes. }\end{array}$ \\
\hline B2 & $\begin{array}{l}\text { Evaluation of experiences until session date, } \\
\text { Overall assessment of the patient's stance toward responsibility, } \\
\text { authenticity and freedom, } \\
\text { Overall assessment of patient's stance toward his/her will to look for } \\
\text { living a meaningful life, } \\
\text { Assessment of patient's approach about habitual reactions and } \\
\text { labeling his/her experiences, } \\
\text { Evaluating how to use new skills in case of relapse and recurrence. }\end{array}$ \\
\hline
\end{tabular}

Notes: Despite following this flowchart, sessions were flexible to some extent, according to patients' needs and circumstances. Hamilton Depression Rating Scale and 20-item Toronto Alexithymia Scale were repeated after W8 and B2. Abbreviations: ExP: existential psychotherapy: W: weekly session; B: booster session. 


\section{Statistics}

While response to the therapy was measured via changes in HDRS and TAS-20 scores, when power analysis was assessed with power value of 0,80 and significance level of 0,05 , a minimum of 16 patients were required for each of three groups. We eventually decided for 22 subjects in each group.

Statistical evaluation of data was done with IBM SPSS Statistics 24 package program. All numerical variables were expressed as either mean ranks or mean \pm standard deviation, while categorical variables were expressed with frequency and possibility tables.

Given more than two independent groups and relatively limited number of subjects $(<30)$ in each group, Kruskal-Wallis was used for comparison of numerical and Chi-Square was used for categorical variables. When a significant difference between groups was detected with Kruskal-Wallis, each group were paired with another and compared with Mann-Whitney U test. Comparisons of groups in themselves were made by Wilcoxon Signed Rank Test. Probability value (p) was taken as $<0.05$ for statistical significance in all statistical analyses.

\section{Results}

All three patient groups and control group were matched in terms of age, gender, marital status and education (Table 1). At the end of the study, mean rank of HDRS scores demonstrated significant differences between patient groups $(\mathrm{p}<0,05)$ (Table 2$)$. When the groups were compared in pairs, there was a significant difference between ExPSUP and CBT-SUP. Thus, HDRS scores were significantly lower than SUP group both in CBT and ExP groups. However, the difference between ExP and CBT groups was not significant (Table 3). When each group is compared in itself with Wilcoxon Signed Rank Test, all patient groups had lower mean scores of HDRS at the end of booster sessions than mean scores at the beginning, while none of the groups' mean HDRS scores changed significantly between the end of weekly sessions and booster sessions (Table 4). Changes in HDRS scores did not differ significantly between therapists in ExP and CBT groups.

While a total score of $\geq 61$ indicates the presence of alexithymia, the number of alexithymic subjects before the sessions start were 2 (9.1\%), 1 (4.5\%) and 3 (13.6\%) for ExP, CBT and SUP respectively. Thus, the total number of alexithymic individuals among patient group was 6 (9.1\%). On the other side, two control subjects (3.0\%) were alexithymic. Despite the clear difference between percentages of alexithymic individuals between patient and control groups, the numbers were not adequate to perform statistical analysis for comparement. For this reason, we decided to compare the groups with regard to TAS-20 total and subscale scores. Patients' mean TAS20 total, TAS- 1 and TAS- 3 scores were greater than of controls at the beginning $(\mathrm{p}<0,05)$, while the difference in mean TAS-2 score was not significant (Table 5). TAS-20 scores of any patient groups did not differ significantly after weekly or booster sessions. Subsequently, comparement of all patient groups in pairs demonstrated that, significant difference of TAS-20 total or subscale scores were neither present at the end of weekly, nor at the end of booster sessions (Table 6). Besides, each group were assessed in terms of alteration of mean TAS-20 scores from the beginning of study to the end. Mean TAS-20 scores of SUP and CBT groups were shown to remain unchanged at the end of weekly and booster sessions. ExP group also did not have significant alteration of TAS-total and subscales, except for TAS-3 (Table 7). Mean TAS-3 scores among ExP group did not show any significant change after weekly sessions, though, change was visible between weekly and booster sessions (Table 7).

We performed Pearson Correlation Test for detection of possible correlation of alexithymia and the response to treatment (Table 8).

Table 1. Comparison of sociodemographic data of patient and control groups

\begin{tabular}{|c|c|c|c|c|c|}
\hline & $\operatorname{ExP}(N=22)$ & $\mathrm{CBT}(\mathrm{N}=22)$ & $\operatorname{SUP}(N=22)$ & Controls ( $N=66$ ) & $p$ \\
\hline Age & $32.2 \pm 12.5$ & $31.6 \pm 10.5$ & $32.2 \pm 11.5$ & $36.2 \pm 10.9$ & 0.164 \\
\hline $\begin{array}{l}\text { Gender } \\
\text { Female }\end{array}$ & $18(81.8 \%)$ & $9(86,4 \%)$ & $18(81.8 \%)$ & $54(81.8 \%)$ & 0.967 \\
\hline $\begin{array}{l}\text { Marital status } \\
\text { Married } \\
\text { Single } \\
\text { Divorced, widow, seperated }\end{array}$ & $\begin{array}{c}8(36,4 \%) \\
12(54,5 \%) \\
2(9,1 \%) \\
\end{array}$ & $\begin{array}{c}6(27,3 \%) \\
14(63,6 \%) \\
2(9,1 \%) \\
\end{array}$ & $\begin{array}{c}10(45.5 \%) \\
11(50.0 \%) \\
1(4.5 \%) \\
\end{array}$ & $\begin{array}{c}18(27.3 \%) \\
41(62.1 \%) \\
7(10.6 \%)\end{array}$ & 0.779 \\
\hline $\begin{array}{l}\text { Education } \\
\text { Literate } \\
\text { Elementary } \\
\text { High school } \\
\text { Associate licence, licence } \\
\text { Post-graduate, doctorate }\end{array}$ & $\begin{array}{c}1(4.5 \%) \\
3(13,6 \%) \\
6(27.3 \%) \\
10(45.5 \%) \\
2(9.1 \%)\end{array}$ & $\begin{array}{c}1(4,5 \%) \\
3(13,6 \%) \\
5(22,7 \%) \\
11(50,0 \%) \\
2(9,1 \%)\end{array}$ & $\begin{array}{c}1(4.5 \%) \\
3(13.6 \%) \\
7(31.8 \%) \\
9(40.9 \%) \\
2(9.1 \%)\end{array}$ & $\begin{array}{c}2(3.0 \%) \\
16(24.2 \%) \\
17(25.8 \%) \\
21(31.8 \%) \\
10(15.2 \%)\end{array}$ & 0.945 \\
\hline
\end{tabular}

Notes: Kruskal-Wallis was used for comparison of numerical data and chi-square test was used for comparison of categorical variables. Ages of groups are expressed as mean \pm standard deviation. Other values are expressed as percentiles. Abbreviations: N: number of subjects; p: probability value; ExP: existential psychotherapy group; CBT: cognitive behavioral therapy group; SUP: supportive counselling group.

Table 2. Comparison of mean HDRS ranks between patient groups

\begin{tabular}{|l|c|c|c|c|}
\hline & ExP $(\mathrm{N}=22)$ & CBT (N =22) & SUP (N =22) & $p$ \\
\hline Bgn & 34.36 & 35.59 & 30.55 & 0.659 \\
\hline Awk & 29.41 & 28.95 & 42.14 & $\mathbf{0 . 0 3 5 ^ { * }}$ \\
\hline ABst & 29.89 & 26.11 & 44.50 & $<0.01^{*}$ \\
\hline
\end{tabular}

Notes: Kruskal-Wallis was used for comparison of numerical data; *Significant difference between groups. Abbreviations: N: number of subjects; p: probability value; ExP: existential psychotherapy group; CBT: cognitive behavioral therapy group; SUP: supportive counselling group; Bgn: mean rank for HDRS scores before the start of sessions; Awk: mean rank for HDRS scores after weekly sessions; ABst: mean rank for HDRS scores after booster sessions. 
Table 3. Paired comparisons of mean HDRS ranks of each patient group

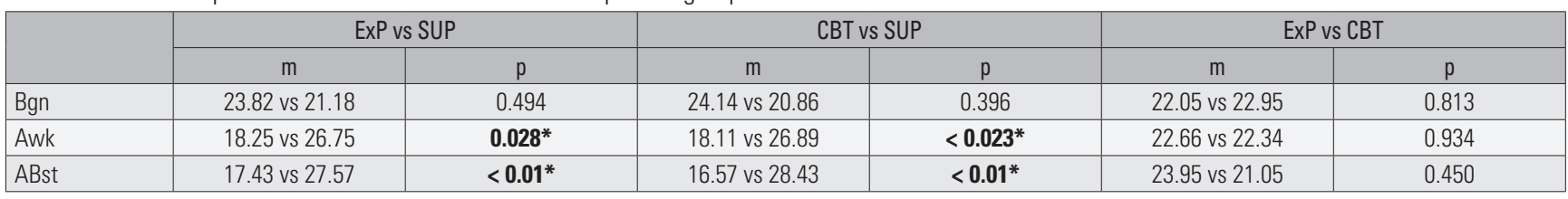

Notes: Mann-Whitney U was used for comparison of numerical data. *Significant difference between groups. Abbreviations: p: probability value; ExP: existential psychotherapy group; CBT: cognitive behavioral therapy group; SUP: supportive counselling group; vs: versus; Bgn: mean values before the start of sessions; Awk: mean values after weekly sessions; ABst: mean values after booster sessions; m: mean rank.

Table 4. Comparisons of mean HDRS scores for all treatment groups in themselves

\begin{tabular}{|l|c|c|c|c|c|c|}
\hline \multirow{2}{*}{} & \multicolumn{2}{|c|}{$\operatorname{ExP}(\mathrm{N}=22)$} & \multicolumn{2}{c|}{ CBT (N=22) } & \multicolumn{2}{c|}{ SUP (N=22) } \\
\cline { 2 - 7 } & mean & $p$ & mean & $p$ & mean & $p$ \\
\hline Bgn vs ABst & $(18.1 \pm 3.6)$ vs $(10.1 \pm 3.4)$ & $<\mathbf{0 . 0 1 *}$ & $(18.4 \pm 3.2)$ vs $(9.2 \pm 3.9)$ & $<\mathbf{0 . 0 1 *}$ & $(17.3 \pm 4.0)$ vs $(13.1 \pm 3.7)$ & $<\mathbf{0 . 0 1 *}$ \\
\hline Bgn vs Awk & $(18.1 \pm 3.6)$ vs $(10.9 \pm 4.6)$ & $<\mathbf{0 . 0 1 *}$ & $(18.4 \pm 3.2)$ vs $(10.9 \pm 5.0)$ & $\mathbf{0 . 0 1 *}$ & $(17.3 \pm 4.0)$ vs $(14.3 \pm 4.9)$ & $<\mathbf{0 . 0 1 *}$ \\
\hline Awk vs ABst & $(10.9 \pm 4.6)$ vs $(10.1 \pm 3.4)$ & 0.526 & $(10.9 \pm 5.0)$ vs $(9.2 \pm 3.9)$ & 0.232 & $(14.3 \pm 4.9)$ vs $(13.1 \pm 3.7)$ & 0.253 \\
\hline
\end{tabular}

Notes: Wilcoxon Signed Rank Test was used for comparison of numerical data. HDRS scores are expressed as mean \pm standard deviation. *Significant difference. Abbreviations: N: number of subjects; p: probability value; ExP: existential psychotherapy group; CBT: cognitive behavioral therapy group; SUP: supportive counselling group; vs: versus; Bgn: mean values before the start of sessions; Awk: mean values after weekly sessions; ABst: mean values after booster sessions.

Table 5. Comparison of mean ranks of TAS-20 total and subscale scores between all groups

\begin{tabular}{|c|c|c|c|c|c|}
\hline & $\operatorname{ExP}(N=22)$ & $\mathrm{CBT}(\mathrm{N}=22)$ & SUP (N = 22) & Control $(\mathrm{N}=66)$ & $p$ \\
\hline \multicolumn{6}{|c|}{ TAS-20 total } \\
\hline Bgn & 84.73 & 80.91 & 83.84 & 49.84 & $<0.01^{*}$ \\
\hline Awk & 32.36 & 31.41 & 36.73 & & 0.618 \\
\hline ABst & 30.95 & 31.57 & 37.98 & & 0.404 \\
\hline \multicolumn{6}{|c|}{ TAS-1 } \\
\hline Bgn & 88.59 & 75.89 & 86.98 & 49.18 & $<0.01 *$ \\
\hline Awk & 34.80 & 28.75 & 36.95 & & 0.336 \\
\hline ABst & 35.23 & 28.66 & 36.61 & & 0.336 \\
\hline \multicolumn{6}{|c|}{ TAS-2 } \\
\hline Bgn & 76.59 & 79.20 & 69.18 & 58.01 & 0.060 \\
\hline Awk & 32.55 & 35.68 & 32.27 & & 0.803 \\
\hline ABst & 32.52 & 34.77 & 33.20 & & 0.922 \\
\hline \multicolumn{6}{|c|}{ TAS-3 } \\
\hline Bgn & 78.23 & 77.30 & 78.80 & 54.89 & $<0.01 *$ \\
\hline Awk & 31.36 & 32.95 & 36.18 & & 0.696 \\
\hline ABst & 29.57 & 33.80 & 37.14 & & 0.421 \\
\hline
\end{tabular}

Notes: Kruskal-Wallis was used for comparison of numerical data. *Significant difference between groups. Abbreviations: N: number of subjects; p: probability value; ExP: existential psychotherapy group; CBT: cognitive behavioral therapy group; SUP: supportive counselling group; TAS-20: 20-item Toronto Alexithymia Scale; TAS-1: Difficulty in Identifying Feelings subscale; TAS-2: Difficulty in Describing Feelings subscale; TAS-3: Externally Oriented Thinking subscale; Bgn: mean ranks before sessions start; Awk: mean ranks after weekly sessions; ABst: mean ranks after booster sessions.

Table 6. Paired comparisons of mean ranks of TAS-20 total and subscale scores after weekly and booster sessions between patient groups

\begin{tabular}{|c|c|c|c|c|c|c|}
\hline & \multicolumn{2}{|c|}{ ExP vs SUP } & \multicolumn{2}{|c|}{ CBT vs SUP } & \multicolumn{2}{|c|}{ ExP vs CBT } \\
\hline & $\mathrm{m}$ & $p$ & $\mathrm{~m}$ & $p$ & $\mathrm{~m}$ & $p$ \\
\hline \multicolumn{7}{|c|}{ TAS-20 total } \\
\hline Awk & 20.77 vs 24.23 & 0.371 & 21.00 vs 24.00 & 0.438 & 23.09 vs 21.91 & 0.760 \\
\hline ABst & 19.95 vs 25.05 & 0.188 & 20.57 vs 24.43 & 0.318 & 22.50 vs 22.50 & 1.000 \\
\hline \multicolumn{7}{|c|}{ TAS-1 } \\
\hline Awk & 21.80 vs 23.20 & 0.714 & 19.75 vs 25.25 & 0.153 & 24.50 vs 20.50 & 0.299 \\
\hline ABst & 21.86 vs 23.14 & 0.741 & 20.02 vs 24.98 & 0.198 & 24.86 vs 20.14 & 0.218 \\
\hline \multicolumn{7}{|c|}{ TAS-2 } \\
\hline Awk & 22.59 vs 22.41 & 0.962 & 23.64 vs 21.36 & 0.553 & 21.45 vs 23.55 & 0.585 \\
\hline ABst & 22.14 vs 22.86 & 0.850 & 23.16 vs 21.84 & 0.731 & 21.89 vs 23.11 & 0.749 \\
\hline \multicolumn{7}{|c|}{ TAS-3 } \\
\hline Awk & 21.07 vs 23.93 & 0.459 & 21.25 vs 23.75 & 0.517 & 21.80 vs 23.20 & 0.744 \\
\hline Abst & 20.30 vs 24.70 & 0.254 & 21.07 vs 23.93 & 0.457 & 20.77 vs 24.23 & 0.370 \\
\hline
\end{tabular}

Notes: Mann-Whitney U was used for comparison of numerical data. *Significant difference between groups. Abbreviations: p: probability value; m: mean rank; ExP: existential psychotherapy group; CBT: cognitive behavioral therapy group; SUP: supportive counselling group; TAS-20: 20-item Toronto Alexithymia Scale; TAS-1: Difficulty in Identifying Feelings subscale; TAS-2: Difficulty in Describing Feelings subscale; TAS-3: Externally Oriented Thinking subscale; Bgn: mean ranks before sessions start; Awk: mean ranks after weekly sessions; ABst: mean ranks after booster sessions. 
Table 7. Comparison of mean values of TAS-20 total and subscale scores for each patient group in themselves

\begin{tabular}{|c|c|c|c|c|c|c|}
\hline & \multicolumn{2}{|c|}{$\operatorname{ExP}(\mathrm{N}=22)$} & \multicolumn{2}{|c|}{$\mathrm{CBT}(\mathrm{N}=22)$} & \multicolumn{2}{|c|}{ SUP $(N=22)$} \\
\hline & mean & $p$ & mean & $p$ & mean & $p$ \\
\hline \multicolumn{7}{|c|}{ Bgn vs ABst } \\
\hline TAS-total & $(44.3 \pm 7.6)$ vs $(42.5 \pm 7.8)$ & 0.066 & $(43.1 \pm 6.9)$ vs $(42.8 \pm 7.2)$ & 0.583 & $(44.7 \pm 10.3)$ vs $(45.4 \pm 9.7)$ & 0.157 \\
\hline TAS-1 & $(14.4 \pm 3.4)$ vs $(13.7 \pm 2.9)$ & 0.304 & $(13.1 \pm 3.3)$ vs $(12.9 \pm 3.2)$ & 0.454 & $(14.4 \pm 3.8)$ vs $(14.3 \pm 3.6)$ & 0.833 \\
\hline TAS-2 & $(11.4 \pm 2.4)$ vs $(11.4 \pm 2.7)$ & 0.802 & $(11.9 \pm 3.0)$ vs $(11.7 \pm 2.4)$ & 0.937 & $(11.2 \pm 3.4)$ vs $(11.6 \pm 3.0)$ & 0.206 \\
\hline TAS-3 & $(18.6 \pm 4.5)$ vs $(17.5 \pm 4.8)$ & $0.045^{*}$ & $(18.1 \pm 3.1)$ vs $(18.2 \pm 3.3)$ & 0.833 & $(19.2 \pm 5.6)$ vs $(19.5 \pm 5.9)$ & 0.399 \\
\hline \multicolumn{7}{|c|}{ Bgn vs Awk } \\
\hline TAS-total & $(44.3 \pm 7.6)$ vs $(43.0 \pm 8.6)$ & 0.163 & $(43.1 \pm 6.9)$ vs $(42.8 \pm 7.5)$ & 0.685 & $(44.7 \pm 10.3)$ vs $(45.2 \pm 10.2)$ & 0.240 \\
\hline TAS-1 & $(14.4 \pm 3.4)$ vs $(13.8 \pm 3.4)$ & 0.232 & $(13.1 \pm 3.3)$ vs $(13.0 \pm 3.3)$ & 0.403 & $(14.4 \pm 3.8)$ vs $(14.5 \pm 3.5)$ & 0.785 \\
\hline TAS-2 & $(11.4 \pm 2.4)$ vs $(11.2 \pm 2.6)$ & 0.496 & $(11.9 \pm 3.0)$ vs $(11.8 \pm 3.0)$ & 0.977 & $(11.2 \pm 3.4)$ vs $(11.3 \pm 3.0)$ & 0.439 \\
\hline TAS-3 & $(18.6 \pm 4.5)$ vs $(18.0 \pm 4.6)$ & 0.219 & $(18.1 \pm 3.1)$ vs $(18.0 \pm 3.3)$ & 0.747 & $(19.2 \pm 5.6)$ vs $(19.4 \pm 5.9)$ & 0.398 \\
\hline \multicolumn{7}{|c|}{ Awk vs ABst } \\
\hline TAS-total & $(43.0 \pm 8.6)$ vs $(42.5 \pm 7.8)$ & 0.220 & $(42.8 \pm 7.5)$ vs $(42.8 \pm 7.2)$ & 1.000 & $(45.2 \pm 10.2)$ vs $(45.4 \pm 9.7)$ & 0.689 \\
\hline TAS-1 & $(13.8 \pm 3.4)$ vs $(13.7 \pm 2.9)$ & 0.747 & $(13.0 \pm 3.3)$ vs $(12.9 \pm 3.2)$ & 0.739 & $(14.5 \pm 3.5)$ vs $(14.3 \pm 3.6)$ & 0.953 \\
\hline TAS-2 & $(11.2 \pm 2.6)$ vs $(11.4 \pm 2.7)$ & 0.317 & $(11.8 \pm 3.0)$ vs $(11.7 \pm 2.4)$ & 0.914 & $(11.3 \pm 3.0)$ vs $(11.6 \pm 3.0)$ & 0.490 \\
\hline TAS-3 & $(18.0 \pm 4.6)$ vs $(17.5 \pm 4.8)$ & $0.045^{*}$ & $(18.0 \pm 3.3)$ vs $(18.2 \pm 3.3)$ & 0.336 & $(19.4 \pm 5.9)$ vs $(19.5 \pm 5.9)$ & 0.793 \\
\hline
\end{tabular}

Notes: Wilcoxon Signed Rank Test was used for comparison of numerical data. Scores of recognized emotions are expressed as mean \pm standard deviation. *Significant difference. Abbreviations: N: number of subjects; p: probability value; m: mean rank; ExP: existential psychotherapy group; CBT: cognitive behavioral therapy group; SUP: supportive counselling group; TAS-20: 20-item Toronto Alexithymia Scale; TAS-1: Difficulty in Identifying Feelings subscale; TAS-2: Difficulty in Describing Feelings subscale; TAS-3: Externally Oriented Thinking subscale; Bgn: mean ranks before sessions start; Awk: mean ranks after weekly sessions; ABst: mean ranks after booster sessions.

Table 8. Significance values (p) for correlations of TAS-20 total and subscale scores with HDRS scores of patients throughout the study

\begin{tabular}{|l|c|c|c|}
\hline & HDRS Bgn & HDRS Awk & HDRS ABst \\
\hline TAS-total & 0.223 & 0.461 & 0.586 \\
\hline TAS-1 & 0.071 & 0.559 & 0.119 \\
\hline TAS-2 & 0.987 & 0.065 & 0.332 \\
\hline TAS-3 & 0.388 & 0.526 & 0.361 \\
\hline
\end{tabular}

Notes: Pearson correlation test was used for the correlations. Abbreviations: HDRS: Hamilton Depression Rating Scale; TAS-20: 20-item Toronto Alexithymia Scale; TAS-1: Difficulty in Identifying Feelings subscale; TAS-2: Difficulty in Describing Feelings subscale; TAS-3: Externally Oriented Thinking subscale; Bgn: correlation significance with HDRS values before sessions start; Awk: correlation significance with $\mathrm{HDRS}$ values after weekly sessions; ABst: correlation significance with $\mathrm{HDRS}$ values after booster sessions.

\section{Discussion}

Depressive disorders relapse frequently, besides, their recurrence rate is remarkable ${ }^{38}$. As time progresses, the tendency to accept depression as a lifelong course is growing. Further, there are editorials supporting this approach ${ }^{39}$. The recurrence rate in first episode depression is reported to be $40 \%$ to $60 \%$ and after the third episode of depression, the rate reaches up to $90 \%{ }^{40}$. Considering the increasing morbidity and mortality by each relapse and recurrence of $\mathrm{MDD}^{41}$, it is of critical importance to choose treatment modalities which seem to be most helpful to prevent from relapses and recurrences.

Classical and third wave CBT were compared with various psychotherapy models for treatment of depression. Some researchers argued that CBT was superior to other psychotherapies ${ }^{42,43}$. In a retrospective follow up of a randomized controlled trial regarding MDD patients with residual symptoms, CBT was found to have short term but not long term benefits ${ }^{44}$. In a different trial assessing the duration of CBT effect upon MDD, effects in prevention of relapse were found to persist, but with weakening, until 3 years after the end of CBT, and subsequent additional CBT was suggested to be explored ${ }^{45}$. Taking into account all of these, while it remains unclear that CBT is superior to other psychotherapies with respect to prevention from MDD, we decided to establish an indirect connection of preventive effect of CBT and certain other psychotherapies via their effect on alexithymia.

As mentioned above, phenomenologic dialogue in $\operatorname{ExP}$ is not a directive process. Thus, ExP does not particularly focus on symptom solving. It is a kind of work up for the process of openness to and looking out for experiences as a whole. Moreover,
ExP does not aim to reduce negative feelings and thoughts or to enhance positive feelings and thoughts. Instead, ExP focuses on directing the patient to negotiate with all dimensions of his/ her experience including feelings, thoughts, bodily senses and realities of the external world ${ }^{46}$. By this way, patient is encouraged to make choices, getting into the action and accepting and taking responsibility of all predictable and unpredictable outcomes ${ }^{47}$. In the current trial, ExP was found to be helpful for treatment of MDD, and also for improvement of externally oriented thinking dimension of alexithymia. The reason why ExP seems to reduce externally oriented thinking between weekly and booster sessions may be the influence of phenomenologic dialogue, which, over time, presumably incites the curiosity of patients on multiple aspects of their physical and relational environment and on their spiritual world. Yet, contrary to the expectation arising from the previous interpretation, ExP did not seem to provide any improvements of identifying and describing own feelings. This finding may be explained with a broader awareness of alexithymia.

Outcomes reported for SUP and CBT in the treatment of depression were found to be comparable in some studies 48 . Contrary to the connotation arising from the word "supportive", SUP does not aim to provide solutions or to become more skilful. It is based on the assumption that, moderating personal problems may be achieved through discussion with other people. Likely in our trial, SUP had a relatively free content, based on a work in which the therapist was rather a friendly listener than a talker. When asked for an assistance concerning the choices about problems of daily life, SUP therapist answered with superficial and short comments in order to find possible choices of the patient 
together. SUP, though less effective than ExP and CBT, was found to be helpful for treatment of MDD. However, at the end of the trial, levels of alexithymia remained unchanged in SUP group.

The etiology of alexithymia is controversial. Some researchers put forward that, alexithymia is more likely to be a personality trait than a pathological condition ${ }^{49}$. Childhood traumas are relatively common among alexithymic individuals, thus, trauma may be the key factor for alexithymia ${ }^{50}$. Genetic factors are also pronounced to have an important role in development of alexithymia ${ }^{51}$. Thus, personality organisation, which is mostly the conclusion of genetics and early life experiences, seems to have a bigger role than recent psychosocial stress in development of alexithymia. This statement partly explains our findings that none of the psychotherapies improved alexithymia significantly.

Alexithymic individuals have difficulty in expressing their psychosocial stress, which leads to a limited chance to get help from other people. Thus, they are prone to feel like lonely and dismissed over time ${ }^{52}$. The term "emotional intelligence (EI)" was originally conceptualised as the ability to perceive accurately, apraise and express emotion; the ability to access and/or generate feelings when they facilitate thought; the ability to understand emotion and emotional knowledge; and the ability to regulate emotions to promote emotional and intellectual growth ${ }^{53}$. This definition seems to include the components of individual intelligence expressed by Gardner, mostly known of which are social intelligence and intrapersonal intelligence ${ }^{54}$. While social intelligence can be conceptualised as the ability to perceive emotions, intentions and desires of others, intrapersonal intelligence can be described as the ability to reach own emotional world. Despite the lack of implication about the ability to perceive other people's emotions and feelings in the definition of alexithymia, experimental studies demonstrated that, alexithymic individuals are having difficulty in recognizing facial emotions of others ${ }^{55,56}$. As it is seen, the term alexithymia may be accepted to have a close conceptual relationship with $\mathrm{EI}^{57}$. Moreover, alexithymic individuals are reported to have difficulty to distinguish different emotional expressions ${ }^{58}$ and to have limited abilities to think functionally and use emotions in the way to cope with stressful situations ${ }^{59}$. Taking into account all of these and our findings, we suggest that, alexithymia might be a constitution in which the individual tends to get depressed more than the general population.

In a study with 33 outpatients who were positive responders to psychotherapy, the TAS-1 subscale was found to predict the severity of residual symptoms, over and above the effect of initial levels of depression and anxiety, form of psychotherapy, and use of antidepressant medication ${ }^{60}$. In another trail, designed as a follow up study, short term psychodynamic psychotherapy (STTP) with mentalization-based techniques was used in MDD patients. A baseline evaluation of reflective functioning, alexithymia and depression was conducted before treatment started. Patients were tested after forty weeks and in a follow up after one year at the end of the treatment. Results demonstrated an improvement of both depression and alexithymia ${ }^{61}$. Our findings did not demonstrate any improvement on alexithymia in CBT and SUP groups, however, a significant improvement was detected for TAS-3 in ExP group. This may partly be a conclusion of relatively short follow up period in our study, because, the improvement of TAS-3 in ExP group was detected in the final part of the study.

An article which summarizes findings from a series of studies that examined the effect of alexithymia on various aspects of psychotherapeutic approaches, reported some tendency for alexithymic patients to prefer group therapy. However, both in individual and group therapies, alexithymia was associated with poor outcome in both traditional psychodynamic psychotherapy and SUP. Moreover, the negative reaction that therapists had toward patients with high levels of alexithymia appeared to be in response to the lack of positive emotions expressed by these patients ${ }^{62}$. In our study, findings did not demonstrate any significant correlation between levels of alexithymia and severity of depression, neither at the beginning, nor after weekly or booster sessions. Thus, alexithymia did not seem to be a predictor of response to the treatment. This interpretation is valid for relatively short period of our study, that is to say, a longer follow up period might have revealed different outcomes.

Current habitudes of daily living directs most of the community to live in urban centers. This in turn provides a culture of hurry, performance, massification, and superficiality in interpersonal relationships. Not surprisingly, this ends up with many types of suffering contained largely in anxiety disorders. On the other hand, psychotherapy, which optimally promises a deeper exploration of problems and finding the causative ground behind the scenes, every so often seems to force itself to meet expectations of the consumption society and ultimately falls into the trap of instantaneous and/or transient healing. Nevertheless, psychotherapy is one of the most effective ways to create greater openness to the expression of patients from a wide range of experience. This proposal directs us to the phenomenological particularity of each individual and it seems to best fit with ExP while phenomenologic dialogue can be defined as a kind of invitation to the individual to let happenings and things to demonstrate themselves just like what actually they are ${ }^{24}$.

Besides, a scientific doubt may be focused on psychotherapeutic approaches which target relatively short psychotherapy durations and relatively quick healing of symptoms, while symptomatic improvement often does not seem to make room for real emotional world of patients as a whole. In view of our findings which are in favor of ExP particularly in the late phase of the current study, we put forward that longer period of time may be needed for necessary deepening of the topics to be worked on the process and eventually to resolve the suffering brought as complaints to be worked in psychotherapy. Additionally, the psychotherapeutic approach of choice to respect for individuality seems to be phenomenology.

Our study has several limitations. At the onset, number of male patients were much less than female patients in all groups. So, we could not be able to compare therapeutic outcomes between genders. Alexithymic subjects (TAS-20 total score $\geq$ 61) were few in number, thus, we could not be able to compare the therapeutic outcomes of them with patients who do not have alexithymia (TAS-20 total score $\leq 51$ ). We did not measure whether reactions of therapists toward patients worsened as the alexithymic level increases or not. Well organized further follow up studies in psychotherapy, preferably with large samples, focusing on therapist reactions is needed. We could compare the therapeutic outcomes of two therapists for ExP and CBT in themselves and did not find any significant difference. However, while there was one therapist for SUP, we did not have the chance to a likely comparison in SUP group. Sample size and number of sessions were relatively small.

\section{Conclusions}

Depressive patients were more alexithymic than healthy controls. CBT and SUP did not promote a reduction in alexithymia. ExP lead to a significant improvement in externally oriented thinking. The improvement observed in patients with alexithymia undergoing ExP was probably due to the greater appreciation of the phenomenological peculiar expressions and the longer period of therapeutic process. Alexithymia might be a personality trait which poses a remarkable risk for the individuals to get depressed. For further lightening of this issue, long term follow up studies with larger samples are needed.

ExP, CBT and SUP all led to a reduction in MDD. ExP and CBT had comparable effects, but both were more effective than SUP. Further studies, preferably with larger samples and long term follow up should be conducted to investigate all these differentials in other psychiatric disorders as well. 


\section{Disclosure}

The authors report no conflicts of interest.

\section{Acknowledgements}

Tezer Kiliçarslan, MD, Irem Gökgöz, MD, Fatma Büşra Parlakkaya, MD, Residents of Psychiatry, Bezmialem Foundation University Medical Faculty, Department of Psychiatry, İstanbul, Turkey (helped for acquisition of data, performed TAS-20).

\section{References}

1. Sifneos PE. The prevalence of 'alexithymic' characteristics in psychosomatic patients. Psychother Psychosom. 1973;22(2):255-62.

2. Kojima M, Senda Y, Nagaya T, Tokudome S, Furukawa TA. Alexithymia, depression and social support among Japanese workers. Psychother Psychosom. 2003;72(6):307-14

3. Suslow T, Rufer M, Kersting A, Guenther V. Predicting symptoms in major depression after inpatient treatment: The role of alexithymia. Eur Psychiatry. 2016;33(Suppl):s524.

4. Nakao M, Takeuchi T. Alexithymia and somatosensory amplification link perceived psychosocial stress and somatic symptoms in outpatients with psychosomatic illness. J Clin Med. 2018;7(5):112.

5. Di Trani M, Mariani R, Renzi A, Greenman PS, Solano L. Alexithymia according to Bucci's multiple code theory: A preliminary investigation with healthy and hypertensive individuals. Psychol Psychother. 2018;91(2):232-47.

6. Sasioglu M, Gulol C, Tosun A. Aleksitimi Kavramı [The Concept of Alexithymia]. Current Approaches in Psychiatry. 2003;5(4):507-27.

7. Joukamaa M, Taanila A, Miettunen J, Karvonen JT, Koskinen M, Veijola J. Epidemiology of alexithymia among adolescents. J Psychosom Res. 2007;63(4):373-6.

8. Mason O, Tyson M, Jones C, Potts S. Alexithymia: its prevalence and correlates in a British undergraduate sample. Psychol Psychother. 2005;78(Pt 1):113-25.

9. Salminen JK, Saarijärvi S, Aärelä E, Toikka T, Kauhanen J. Prevalence of alexithymia and its association with sociodemographic variables in the general population of Finland. J Psychosom Res. 1999;46(1):75-82.

10. Murray CJ, Lopez AD. Alternative projections of mortality and disability by cause 1990-2020: Global Burden of Disease Study. Lancet. 1997;349(9064):1498-504.

11. Walker ER, McGee RE, Druss BG. Mortality in mental disorders and global disease burden implications: a systematic review and metaanalysis. JAMA Psychiatry. 2015;72(4):334-41.

12. Beck A, Rush A, Shaw B, Emery G. Cognitive Therapy of Depression. New York, NY: The Guilford Press; 1979.

13. Beck AT. The current state of cognitive therapy: a 40-year retrospective. Arch Gen Psychiatry. 2005;62(9):953-9.

14. Beck J. Cognitive Behavior Therapy: Basics and Beyond. New York, NY: The Guilford Press; 2011.

15. Cuijpers P, Hollon SD, van Straten A, Bockting C, Berking M, Andersson G. Does cognitive behaviour therapy have an enduring effect that is superior to keeping patients on continuation pharmacotherapy? A metaanalysis. BMJ Open. 2013;3(4):e002542.

16. Kahl KG, Winter L, Schweiger U. The third wave of cognitive behavioural therapies. Curr Opin Psychiatry. 2012;25(6):522-8.

17. Podina IR, David D. Acceptance and Commitment Therapy. In: Vernon A, Doyle KA, eds. Cognitive Behavior Therapies: A Guidebook for Practitioners. Alexandria, VA: Wiley- American Counseling Association; 2018. p. 177-208.

18. Greenberg J, Shapero BG, Mischoulon D, Lazar SW. Mindfulnessbased cognitive therapy for depressed individuals improves suppression of irrelevant mental-sets. Eur Arch Psychiatry Clin Neurosci. 2017;267(3):277-282

19. Steiner CJ, Reisinger Y. Understanding existential authenticity. Ann Tourism Res. 2006;33(2):299-318.

20. Schnell T. Existential indifference: another quality of meaning in life. J Hum Psychol. 2010;50(3):351-73.

21. Rae G. Sartre, Group Formations, and Practical Freedom. In: Realizing Freedom: Hegel, Sartre, and the Alienation of Human Being. London: Palgrave Macmillan; 2011. p. 91-109.
22. Danner H. Existential Responsibility - The Civic Virtue. Studies in Philosophy and Education. 1998;17(4):261-70.

23. Dearborn Nill J, Halling S. A Brief History of Existential - Phenomenological Psychiatry and Psychotherapy. Journal of Phenomenological Psychology. 1995;26(1):1-45.

24. Arnett RC. Toward a phenomenological dialogue. West J Comm. 1981;45(3):201-12.

25. Frankl VE. Logotherapy and existential analysis - a review. Am J Psychother. 1966;20(2):252-60.

26. DiPetta G. Addictions and depression: the paradise lost. Eur Psychiatry. 2015;30(1):114.

27. Ventegodt S, Clausen B, Langhorn M, Kromann M, Andersen NJ, Merrick J. Quality of life as medicine III. A qualitative analysis of the effect of a five-day intervention with existential holistic group therapy or a quality of life course as a modern rite of passage. ScientificWorldJournal. 2004;4:124-33.

28. Reiter MD, Chenail RJ, eds. Behavioral, humanistic-existential, and psychodynamic approaches to couples counseling. New York, NY: Taylor \& Francis; 2017.

29. Cuijpers P, Driessen E, Hollon SD, van Oppen P, Barth J, Andersson G. The efficacy of non-directive supportive therapy for adult depression: a meta-analysis. Clin Psychol Rev. 2012;32(4):280-91.

30. Barth J, Munder T, Gerger H, Nüesch E, Trelle S, Znoj H, et al. Comparative efficacy of seven psychotherapeutic interventions for patients with depression: a network meta-analysis. PLoS Med. 2013;10(5):e1001454.

31. First MB, Spitzer R, Giboobn M, Williams J. Structed Clinical Interview for DSM IV Axis Disorders (SCID-1 SCID-I) Clinical Version. Washington DC, WA: American Psychiatric Press; 1997.

32. Özkürkçügil A, Aydemir O, Yıldız M, Esen-Danaci A, Köroğlu E. DSM-IV Eksen I bozuklukları için yapılandırılmış klinik görüşmenin Türkçeye uyarlanması ve güvenilirlik çalışması. İlaç ve Tedavi Dergisi. 1999;12(4):233-6.

33. Hamilton M. A rating scale for depression. J Neurol Neurosurg Psychiatry. 1960;23:56-62.

34. Williams JB. A Structured Interview Guide for the Hamilton Depression Rating Scale. Arch Gen Psychiatry. 1988;45(8):742-7.

35. Akdemir A, Türkçapar MH, Orsel SD, Demirergi N, Dag I, Ozbay MH. Reliability and validity of the Turkish version of the Hamilton Depression Rating Scale. Compr Psychiatry. 2001;42(2):161-5.

36. Bagby RM, Parker JD, Taylor GJ. The twenty-item Toronto Alexithymia Scale - I. Item selection and cross-validation of the factor structure. J Psychosom Res. 1994;38(1):23-32.

37. Güleç H, Köse S, Güleç M, Çitak S, Evren C, Borckardt J, Sayar K. Reliability and factorial validity of the Turkish version of the 20-item Toronto alexithymia scale (TAS-20). Klinik Psikofarmakoloji Bülteni. 2009;19(3):214-20.

38. Monroe SM1, Harkness KL. Recurrence in major depression: a conceptual analysis. Psychol Rev. 2011;118(4):655-74.

39. Scott J. Depression should be managed like a chronic disease. Br Med J. 2006;332(7548):985-6.

40. Moffitt TE, Caspi A, Taylor A, Kokaua J, Milne BJ, Polanczyk G, et al. How common are common mental disorders? Evidence that lifetime prevalence rates are doubled by prospective versus retrospective ascertainment. Psychol Med. 2010;40(6):899-909.

41. Keller MB, Boland RJ. Implications of failing to achieve successful longterm maintenance treatment of recurrent unipolar major depression. Biol Psychiatry. 1998;44(5):348-60.

42. Eysenck HJ. The outcome problem in psychotherapy: what have we learned? Behav Res Ther. 1994;32(5):477-95.

43. Shapiro DA, Shapiro D. Meta-analysis of comparative therapy outcome studies: A replication and refinement. Psychol Bull. 1982;92(3):581-604.

44. Perlis RH. Cognitive behavioural therapy has short term but not long term benefits in people with residual symptoms of depression. Evid Based Ment Health. 2005;8(3):75.

45. Paykel ES, Scott J, Cornwall PL, Abbott R, Crane C, Pope M, et al. Duration of relapse prevention after cognitive therapy in residual depression: follow-up of controlled trial. Psychol Med. 2005;35(1):59-68.

46. Reker GT. Personal meaning, optimism, and choice: existential predictors of depression in community and institutional elderly. Gerontologist. 1997;37(6):709-16 
47. Kuhl J, Koole S. Workings of the will: a functional approach. In: Greenberg J, Koole S, Pyszczynski T, eds. Handbook of experimental existential psychology. New York, NY: The Guilford Press; 2004. p. 411-30.

48. Pybis J, Saxon D, Hill A, Barkham M. The comparative effectiveness and efficiency of cognitive behaviour therapy and generic counselling in the treatment of depression: evidence from the 2nd UK National Audit of psychological therapies. BMC Psychiatry. 2017;17(1):215.

49. Salminen JK, Saarijärvi S, Toikka T, Kauhanen J, Aärelä E. Alexithymia behaves as a personality trait over a 5-year period in Finnish general population. J Psychosom Res. 2006;61(2):275-8.

50. Berenbaum H. Childhood abuse, alexithymia and personality disorder. J Psychosom Res. 1996;41(6):585-95.

51. Jørgensen MM, Zachariae R, Skytthe A, Kyvik K. Genetic and environmental factors in alexithymia: a population-based study of 8,785 Danish twin pairs. Psychother Psychosom. 2007;76(6):369-75.

52. Taylor GJ. Recent developments in alexithymia theory and research. Can J Psychiatry. 2000;45(2):134-42.

53. Salovey P, Mayer JD. Emotional Intelligence. Imag Cogn Pers. 1990;9(3):185-211.

54. Gardner H. Multiple intelligences: prelude, theory and aftermath. In: Sternberg R, Fiske S, Foss D, eds. Scientists making a difference. New York, NY: Cambridge University Press; 2016. p. 167-70.
55. Lane RD, Sechrest L, Reidel R, Weldon V, Kaszniak A, Schwartz GE. Impaired verbal and nonverbal emotion recognition in alexithymia. Psychosom Med. 1996;58(3):203-10.

56. Parker JD, Taylor GJ, Bagby RM. Alexithymia and the recognition of facial expressions of emotion. Psychother Psychosom. 1993;59(3-4):197-202.

57. Parker JD, Taylor GJ, Bagby RM. The relationship between emotional intelligence and alexithymia. Pers Individ Dif. 2001;30(1):107-15.

58. Bagby RM, Parker JDA, Taylor GJ, Acklin MW. Alexithymia and the ability to distinguish different emotional states. Psychother Psychosom. 1993;55:122.

59. Parker JD, Taylor GJ, Bagby RM. Alexithymia: relationship with ego defense and coping styles. Compr Psychiatry. 1998;39(2):91-8.

60. Ogrodniczuk JS, Piper WE, Joyce AS. Alexithymia as a predictor of residual symptoms in depressed patients who respond to short-term psychotherapy. Am J Psychother. 2004;58(2):150-61.

61. Bressi C, Fronza S, Minacapelli E, Nocito EP, Dipasquale E, Magri L, et al. Short-Term Psychodynamic Psychotherapy with Mentalization-Based Techniques in Major Depressive Disorder patients: Relationship among alexithymia, reflective functioning, and outcome variables - A Pilot study. Psychol Psychother. 2017;90(3):299-313.

62. Ogrodniczuk JS, Piper WE, Joyce AS. Effect of alexithymia on the process and outcome of psychotherapy: a programmatic review. Psychiatry Res. 2011;190(1):43-8. 